\title{
The Comparative Analysis of Mediation and IT Technical Terms: Evaluative Meaning
}

\section{Alina Gennadyevna Chernyshenko}

\section{Maksim Nikolaevich Latu}

\author{
Pyatigorsk State Linguistic University, Stavropol region, 357532, Pyatigorsk, Kalinina avenue, 9
}

\author{
Doi:10.5901/mjss.2015.v6n6s3p83
}

\begin{abstract}
This paper presents the comparative analysis of the process of coining technical terms in the terminology of mediation and information technologies, some structural and semantic peculiarities of the technical terms are put into context and discussed. Mediation and IT terminologies were subjected to the Nuclear-Peripheral analysis as most of the crucial controversies in term translation are related to the shift of the original meaning of the terminological element that is the nucleus or misinterpretation of the meaning of a terminological element that represents the periphery in technical term structure. The qualitative method was used to reveal the statistics for the detected regularities and the distribution within the terminologies. This article addresses the need for research on specific characteristics of terminologies of fundamental and applied character for further elaboration of the principles for systematization and standardization of developing terminological systems.
\end{abstract}

Keywords: mediation terminology; IT terminology; semantics; structural analysis, evaluative meaning.

\section{Introduction}

Recent studies in linguistics have proved that language represents both the process and the result of cognitive activity (Clark, 1996) that also presumes accumulation and transfer of knowledge. Technical terms are language units that fulfill these functions within specific areas of academic and professional knowledge. According to D. Crystal there is a need for technical terms in everyday life and we extend our knowledge by acquiring technical terms for some areas of living. As general language may be prone to ambiguity, technical terms are precise (Crystal, 2007). But technical terms also appear diverse in coining patterns and semantic features in various fields of knowledge. Terms in social sciences and humanities differ from those in medicine or technics due to the specificity of the subject and peculiarities of the notions they express (Zhukhov, 2013). Nanotechnology is reach in technical terms that have terminological element nano- that does not appear to be productive or is not represented in other terminologies (Razduev, 2013; \& Latu, 2014). Zoology is specific in doubling or even tripling of the root morpheme, i.e. sprattus sprattus sprattus, that generally does not occur in other terminologies. Chemistry is famous in having really long multi-component agglutinative technical terms (Grinev-Grinevich, 2008). Still technical terms share some common features that define them as such. Some features may be of different productivity such as eponymic terms that have eponyms in their structure, i.e. van der Waals forces, etc. (Razduev, 2015). Understanding the specificity of knowledge representation in various fields becomes possible by comparing them especially those that are not related, such as the terminology of mediation (MT) that is related to, stems from and shares a lot in common with the terminology of jurisprudence and information technologies terminology (ITT).

\section{Method and Methodology}

As the article is devoted to a comparative analysis of the process of coining technical terms in the terminology of mediation and information technologies, some structural and semantic peculiarities of the technical terms are put into context and discussed. Our approach is to define some common features and regularities as well as specific ones to each of the terminologies. The primary method in this respect is comparative analysis. The technical terms for the analysis were singled out from previously built terminological data bases of the mentioned fields of knowledge. As the component and definition analysis were applied, the technical terms were classified to define the structural types based on the number of components as well as the semantic types. The frame analysis was carried out to define the dispersal of the technical terms in the terminologies and the categories of the notions they express. The qualitative method was used to reveal the statistics for the detected regularities and the distribution within the terminologies.

The three classical stages of linguistic research (collection, analysis and explanation) are put forward. One of the 
problems related to MT and ITT systematization is that both terminologies are relatively young and are developing very quickly. Apart from that MT is generally represented only in a form of short glossaries. Thus, the first objective was to collect data from all the resources possible. 903 terms were collected in the course of real mediation sessions; 1360 units were extracted from the mediation text corpus that consists of 6254 articles, 3598 mediation documents as well as 3403 publications and reports by mediation associations, advisory councils which cover standards for mediation. As for the ITT terminology technical terms were extracted from specialized texts and documents. For more convenient analysis of the technical terms, electronic MT and ITT databases were built systemized according to the following criteria: field of use, structural type, term-formation type, number of components, eponymy, definition, semantic type, context samples, motivation, abbreviation, synonyms, antonyms, hypernyms and hyponyms, etc.

The study of MT and ITT was carried out in accordance with the following stages of the analysis of terminological units: 1) analysis of the component structure of each term; 2) part of speech identification; 3) identification of the dominant element in a terminological set and classification of the terms into substantive, attributive and verbal; 4) analysis of mono-component terms' formative structure.

Mediation and IT terminologies were also subjected to the Nuclear-Peripheral analysis. In fact, most of the crucial controversies in term translation are related to the shift of the original meaning of the terminological element that is the nucleus or misinterpretation of the meaning of a terminological element that represents the periphery in technical term structure. Although semantic structure of English terms and their Russian variants is not always identical and may vary, central semantic component of the nuclear area must be always preserved in order to provide adequate equivalents. Hence, some of the mediation terms translated into Russian copy semantic pattern of the originally English term (1)

(1) Eng. Transformative periphery + mediation $^{\text {nucleus }}$

(uninuclear with periphery)

Rus. Преобразующая ${ }^{\text {periphery }}+$ медиация ${ }^{\text {nucleus }}$

(uninuclear with periphery)

while some models undergo transformations (the necessity to add more words and thus extend the periphery area, introduction of prepositions and other additional components according to grammatical rules), however, preserving the nucleus (2).

(2) Eng. Lawyer ${ }^{\text {periphery(1) }} /$ supported $^{\text {periphery(2) }}+$ mediation $^{\text {nucleus }}$

(uninuclear with expanded periphery)

Rus. Медиация ${ }^{\text {nucleus }}+c^{\text {additional component }}+$ участиием ${ }^{\text {periphery(2) }} /$ адвоката ${ }^{\text {periphery(1) }}$

(uninuclear with expanded periphery and additional component)

\section{Results and Discussion}

A considerable part of the lexis in mediation and IT discourses is represented by the terms which were coined according to special structural and cognitive models in order to achieve specific discourse purposes. Mediation terminology and IT terminology can be characterized as open sets of professional and technical words or expressions which denote the core concepts of the mentioned practices which are seen as cognitive-communicative systems.

In order to define what structural models can be accepted as structural standards, all patterns, functioning within MT and ITT, were tracked down and subjected to a quantitative analysis. Among the parameters taken into account were: frequency of models representation and the productivity of the patterns in building new terms. Apart from that structural analysis of MT and ITT technical terms allowed to draw some general conclusions about term-formation tendencies within the terminologies:

1) Mono-component terms $(14.32 \%$ for MT and $24.7 \%$ for ITT) appear to be a minority while quantitative preference is given to multi-component terms (85.68\% and $75.3 \%$ respectively) with complex structure that does not compromise their understandability and psychological acceptability. Prolonged definition-like constructions of 5-6 components are not typical for MT. However, the structure of $7.87 \%$ of IT-terms includes 4-6 components.

2) The analysis of MT indicated that terminological units from other SFTs (subject field terminology) in $19.4 \%$ of cases are used as building material for two- and three-component mediation terms. Predominantly these are terms (or parts of complex terms) presenting psychological concepts (cognitive, escalation etc.) and legal terms which get into the structure of mediation multi-component terms as attributes. Borrowed units which build $9.59 \%$ of multi-component IT terms come from physics (quantization), linguistics (operational semantics, denotational semantics, hypertext, semantic interface, syntax etc.) and postal terminology (physical address, communication line, E-mail etc.). 
3) The overall analysis of MT showed that syntactic term-formation (73.6\%) dominates over morphological (7.02\%) and morphosyntactic (19.31\%) term-formation (see Table 1). The most productive structural models of MT are Adj.+N (14\%), N+N (9.5\%) and Participle II+N (8.9\%). In 39.5\% of all the cases formation of multi-word combinations is due to the "extension" of a term of the previous level in the hierarchy of classification (party=>third party-=>third party intervention). The extension-pattern was also tracked down in ITT (48.6\% of multi-component terms). High productivity of certain terms allows them to form "nests" that number dozens of multi-component terms (file=>file system $=>$ Flash File System (FFS) $=>$ Yet Another Flash File System(YAFFS). $6.5 \%$ of the mediation terms and $20.6 \%$ of IT terms are derivatives. $67 \%$ of all the abbreviations used in MT (4.63\%) are acronyms and function as independent words. This trend is also typical for abbreviated IT terms -4.9\%- (FUSE, Cramfs, MooseFS, JFFS2). Mediation terms formed by specialization of meaning (2.2\%) are more common for written speech in mediation; neology has not been traced.

Table 1 - Structural Models of IT Terminology and Mediation Terminology

\begin{tabular}{|c|c|c|c|c|c|c|}
\hline Structural Models & $\begin{array}{l}\text { Number of } \\
\text { Terms (MT) } \\
\end{array}$ & $\begin{array}{c}\text { Percentage } \\
\text { (MT) }\end{array}$ & $\begin{array}{l}\text { Productiveness } \\
\text { (MT) }\end{array}$ & $\begin{array}{c}\text { Number of } \\
\text { Terms (ITT) }\end{array}$ & $\begin{array}{c}\text { Percentage } \\
\text { (ITT) }\end{array}$ & $\begin{array}{l}\text { Productiveness } \\
\text { (ITT) }\end{array}$ \\
\hline $\begin{array}{l}\text { Morphological term-formation } \\
\text { Derivation }\end{array}$ & $\begin{array}{l}159 \\
148\end{array}$ & $\begin{array}{l}7.02 \\
6.50\end{array}$ & & $\begin{array}{l}308 \\
308\end{array}$ & $\begin{array}{c}20.6 \\
20.60\end{array}$ & \\
\hline Pref. $+\mathrm{N}$ & 43 & 1.90 & low & 165 & 11.0 & high \\
\hline $\mathrm{N}+$ Suf. & 54 & 2.38 & low & 86 & 5.7 & relatively high \\
\hline Pref.+N+Suf. & 51 & 0.92 & low & 57 & 3.8 & low \\
\hline Conversion & 11 & 0.48 & & 0 & 0 & - \\
\hline $\mathrm{N}$ to $\mathrm{V}$ & 0 & 0 & - & 0 & 0 & - \\
\hline$V$ to $\mathrm{N}$ & 11 & 0.48 & critically low & 0 & 0 & - \\
\hline Syntactic term-formation & 1667 & 73.6 & & 847 & 56.8 & \\
\hline $\mathrm{N}+\mathrm{N}$ & 215 & 9.50 & high & 123 & 8.20 & high \\
\hline N+ Participle I & 138 & 6.09 & high & 158 & 10.6 & high \\
\hline Adj. $+\mathrm{N}$ & 317 & 14.0 & high & 203 & 13.60 & high \\
\hline Participle II+N & 202 & 8.90 & high & 99 & 6.64 & relatively high \\
\hline Adj. +N+ Participle I & 105 & 4.63 & relatively high & 49 & 3.20 & low \\
\hline Adj. + Participle I & 58 & 2.56 & low & 35 & 2.30 & low \\
\hline $\mathrm{N}+\mathrm{N}+\mathrm{N}$ & 109 & 4.81 & relatively high & 26 & 1.70 & low \\
\hline $\mathrm{N}+\mathrm{N}+$ Participle I & 97 & 4.20 & relatively high & 59 & 3.96 & low \\
\hline $\mathrm{N}+$ Participle I+ N & 45 & 2.03 & Low & 62 & 4.16 & low \\
\hline Participle II+N+N & 107 & 4.72 & relatively high & 12 & 0.80 & critically low \\
\hline Adj.+N+N & 138 & 6.09 & relatively high & 56 & 3.76 & low \\
\hline $\mathrm{N}+\mathrm{N}+\mathrm{N}+\mathrm{N}$ & 38 & 1.67 & low & 14 & 0.94 & critically low \\
\hline Participle II +N+N+N & 48 & 2.12 & low & 7 & 0.47 & critically low \\
\hline Morphosyntactic term-formation & 437 & 19.31 & & 301 & 20.20 & \\
\hline Compound & 102 & 4.50 & relatively high & 81 & 5.43 & relatively high \\
\hline Adj.+Compound & 113 & 4.99 & relatively high & 75 & 5.03 & relatively high \\
\hline Adj.+Compound +N & 103 & 4.55 & relatively high & 57 & 3.80 & low \\
\hline Blending & 2 & 0.08 & critically low & 3 & 0.20 & critically low \\
\hline Ellipse & 6 & 0.26 & critically low & 0 & 0 & - \\
\hline Abbreviation & 105 & 4.63 & relatively high & 73 & 4.90 & relatively high \\
\hline Clipping & 6 & 0.26 & critically low & 0 & 0 & - \\
\hline Back-formation & 0 & 0 & - & 0 & 0 & - \\
\hline \multicolumn{7}{|l|}{ Other } \\
\hline Neology & 0 & 0 & - & 0 & 0 & critically low \\
\hline Specialization & 50 & 2.20 & Low & 12 & 0.80 & critically low \\
\hline Total & 2263 & 100.00 & & 1489 & 100.00 & \\
\hline
\end{tabular}

The obvious prevalence of multi-component term patterns (Participle II $+\mathrm{N}+\mathrm{N}+\mathrm{N}$, Adj. $+\mathrm{N}+$ Participle, Adj. $+\mathrm{N}+\mathrm{N}$ ect.) with the central generic element in both terminologies attests to complex cognitive relations between the terms.

The results from the structural analysis allow us to make some comments on the nature of the terms that represent concepts of the mediation practice. Firstly, MT includes general legal terms: some of them presume the meaning they have acquired in the legal discourse; some are being concretized as they enter the mediation process, particularly various specific procedures of mediation (family mediation, peer mediation, custody mediation, divorce mediation). The majority of mediation terms (85.68\%) are multi-component combinations, often (37.8\%) involving more than two elements. In many cases, multi-component terms designate concepts that reflect the actual ties between mediation and other dispute resolving practices (conflictology, psychology, law, economy etc.), terms which are borrowed from adjacent fields of study enter terminological sets as building elements. 
Despite the low productivity of the derivative formation within MT and ITT, the figures from morphological analysis show that it is possible to identify 4 representative patterns. The formation of mediation and IT terms involves prefixes with the following meanings: 1) negative meaning (disarming strategies, defamation, non-binding arbitration, defragmentation, antivirus program); 2) combining (co-mediation, co-working, co-building strategies); 3) repetition (backlash, reorganization process, redirect); 4) sequence (pre-hearing review, post-mediation blues, preselector).

From the standpoint of etymology $45.69 \%$ of derived mediation terms have suffixes of Romanesque origin (the most productive - tion), Greek prefixes and suffixes: re-, de-, dis; -ing, -ity, -ment, -er / -or.

A small number of mediation terms $(0.69 \%)$ is formed by the following semantic models: metaphorization («Open Shop» agreement / settlement- open shop; an agreement to open the shop; «Framing» - defining the problem in dispute; «Frames» - identified problems), specialization and extension of the meaning which is not typical for ITT.

The semantic analysis showed that a greater part of mediation terms (75.43\%) are uninuclear terms with periphery with the nuclear meaning presented by a noun ( $98.7 \%)$ and periphery expressed by adjectives (36.82\%) and Participle I $(12.32 \%)$ and Participle II (6.84\%). The second position is occupied by uninuclear terms (14.9\%) which designate abstract concepts, types of sessions and names of participants while the number binuclear terminological (7.1\%) units is extremely small (Table 2).

Table 2 - Semantic Models of English MT

\begin{tabular}{lc}
\hline Semantic Models of MT & Percentage \\
\hline Uninuclear & 14.90 \\
Uninuclear with periphery & 75.43 \\
Uninuclear with periphery and additional components & 2.57 \\
Binuclear & 7.10 \\
\hline Total & $\mathbf{1 0 0 . 0 0}$ \\
\hline
\end{tabular}

The analysis of ITT suggests that there are 19.5\% uninuclear IT terms while the semantic model "uninuclear with periphery" is the most frequent $-66.3 \%$. Binuclear terminological units are comparatively rare $-4.5 \%$ (Table 3 ).

Table 3 - Semantic Models of English ITT

\begin{tabular}{lc}
\hline Semantic Models of ITT & Percentage \\
\hline Uninuclear & 19.50 \\
Uninuclear with periphery & 66.30 \\
Uninuclear with periphery and additional components & 9.70 \\
Binuclear & 4.50 \\
\hline Total & 100.00 \\
\hline
\end{tabular}

The analyzed specialized language units which are mostly represented by compound nominal forms, do not just stand for the concepts within two special domains (mediation and IT) but reflect the propositional relations within the text and the conceptual relations between concepts of the domain. The terms of the terminologies under consideration have the potential to establish synonymous and antonymous relations and form groups according to the presence or absence of the semantic opposition reflected in the underlying form. They are characterized by clear or obscure motivation of the underlying form, as well as the presence of evaluative component of the meaning in the semantics.

When looking at a phenomenon, act or task one tends to evaluate it in terms of how it meets with his individual system of desires, passions and fears. If there is an evaluative connotation in the term semantics, it reflects the attitude of an individual who was giving a name to a concept, for the cognitive evaluation is switched on through self-perception. It must be noted that the analysis showed that semantic structure of IT terms contains no evaluation while some mediation terms can be marked as "positive" and some as "negative". In MT there are terms with explicitly expressed negative evaluation - 2.7\% (e.g. "Bad Faith", negative intimacy) and terms with implicit evaluation - 3.8\% (e.g. mala fides, disarming strategies, lose-lose situations, punitive damages). However, positive evaluation in mediation terms is never explicit ("bona fide", win-win situations, restorative justice).

We can assume on the basis of the comparative analysis of "evaluation" in the semantics of ITT and MT that the absence of IT terms with "internal evaluation" suggests that this semantic component is not relevant for some terminologies. Absence or presence of "evaluation" in terms of a specific domain is determined by the parameters 
specifying the functioning of the relevant professional or scientific discourse model that uses the terms as building units. Thus, terms that shape formal procedures are less likely to have "evaluative components" in their semantic structure.

\section{Conclusion}

The analysis has proved that both mediation and IT technical terms share some common features. Thus, at large the statistics for the number of structural components reflects the general trend in other terminologies, when multi-component technical terms predominate over the one-component technical terms. As the terminology keeps expanding the number of multi-component terms grows because many new terms are structurally based on the already existing ones in the terminology reflecting the relationship with the generic term. This gives right to claim that technical terms in their majority (though not originally) are word combinations rather than just words. Two-component terms are the most numerous group and the percentage of language units goes down as the number of components grows. However long technical terms are more typical for IT terminology.

The study has also revealed that term elements that build up the structure of the technical terms in mediation and IT are borrowed from different productive fields and subject areas, i.e. linguistics in IT and jurisprudence in mediation. Taking into account the historical development of the terminologies and the specificity of the notions thy express the reasons for such close contacts seem obvious. The statistics reflecting the distribution of structural models and methods of technical term formation (represented in Table 2) clearly illustrates that syntactic term-formation predominates over morphological and morphosyntactic term-formation in both terminologies. The percentage of technical terms representing the structural models varies and in certain cases is low or high for both terminologies, i.e. abbreviation. The specificity of IT terminology in this respect is that some technical terms are build up on such abbreviated terms.

As for the semantic analysis, the majority of the technical terms in mediation and IT terminologies are motivated English terms with little transliterated borrowings from other languages because both fields were actively developing in the English-speaking countries. The statistics reflecting the distribution of the semantic models of technical terms generally coincides for both terminologies with the uninuclear with periphery semantic model being the most productive. The analysis also helped to define that the underlying form of some mediation technical terms contains positive or negative connotations that may be both explicit and implicit. The percentage of such terms is however relatively low. As for the IT terminologies no such connotations were detected in technical terms but they are very typical for professional jargon.

\section{Acknowledgements}

The authors express their gratitude to Ministry of education and science of the Russian Federation that financially supported the study (project \# 2511; project \#14.Z56.14.4389-MK)

\section{References}

Clark, H.H. (1996). Using language. Cambridge: Cambridge University Press.

Crystal, D. (2007). Words, Words, Words. Oxford: Oxford University Press.

Grinev-Grinevich, S.V. (2008). Terminology study. Moscow: Academy.

Høy, A. (2000). Morphological Considerations Concerning the Nationalisation of Medical Terms. Hermes, Journal of Linguistics No. 25.

Latu, M.N. (2014). The role of productive term elements in new technical terms creation. Sovremennye problemy nauki i obrazovaniâ, \#6. Retrieved from www.science-education.ru/120-15459

Razduev, A.V. (2013). Contemporary English nanotechnology terminology: structural, semantic, cognitive-frame and lexicographic models (PhD thesis). Pyatigorsk State Linguistic University, Russia.

Razduev, A.V. (2015) Modern English language nanotechnology terminology in the anthropocentric aspect. Issues of cognitive linguistics., № 1 (042) (143-149).

Streiter, O., Voltmer, L. (2003). A Model for Dynamic Term Presentation, TIA-2003 Conference, Strasbourg.

Zhukhov, O.R. (2014). Towards the issue of comparing technical terms in humanities and natural sciences. Bulletin of Medical Internet Conferences. V(3). Issue 3. Retrieved from http://medconfer.com/node/2347

Chernyshenko A. Russian Mediation Terminology database 2015620418

Chernyshenko A., Latu M. Russian IT Terminology in terms of terminological nomination 2015620095 